\title{
Sección ultrabaja de recto en un tiempo por vía laparoscópica*
}

\author{
Drs. GINO CASELLI M. ${ }^{1}$, GONZALO URREJOLA S. ${ }^{~}$, PATRICIO SALAS P. ${ }^{1}$, FELIPE BELLOLIO R. ${ }^{1}$, \\ ÁlVARO ZÚÑIGA D. ${ }^{1}$, MARÍA ELENA MOLINA P. ${ }^{1}$, GEORGE PINEDO M. ${ }^{1}$
}

1 Departamento de Cirugía Digestiva Pontificia Universidad Católica de Chile. Santiago, Chile.

\section{Totally laparoscopic ultralow section of the rectum}

\section{Introducción}

La técnica quirúrgica aceptada, descrita por Heald et al, implica la disección completa del mesorrecto en conjunto con la sección del recto con margen libre de tumor ${ }^{1}$. Inicialmente el cáncer de recto fue considerado como una contraindicación para el abordaje laparoscópico, avalado por la supuesta dificultad en la sección o corte del tercio inferior del recto, lo que además estaba asociado a una disección pelviana dificil y profunda. Desde la introducción de la laparoscopia en coloproctología, la sección del recto inferior había sido realizada mediante instrumentos que se utilizaban en cirugía abierta a través de una minilaparotomía. Sin embargo, en muchos casos, la obtención de una buena visión seguía siendo dificultosa. El uso de engrapadoras lineales no logró disminuir la complejidad que representaba la sección a nivel del tercio inferior del recto. Así, el advenimiento de las engrapadoras curvas permitió una mayor facilidad técnica, con corte, engrapado y sección simétrica del recto en un solo tiempo ${ }^{2}$. El sistema de corte y engrapado curvo (Contour Curved Cutter Stapler ${ }^{\circledR}$; Ethicon Endosurgery Inc., Cincinnati, $\mathrm{OH}$ ) fue creado inicialmente para la cirugía abierta, pero su utilización ha sido traspasada a la cirugía laparoscópica, ya que otorga una buena visualización de la pelvis y una importante magni- ficación del campo operatorio, lo que asociado a la fácil maniobrabilidad del dispositivo, permite una sección y anastomosis segura.

\section{Técnica quirúrgica}

Bajo anestesia general y con antibióticos preoperatorios (cefotaxima $1 \mathrm{gr}$ iv y metronidazol 500 mg iv 30 minutos previo a la cirugía), el procedimiento se inició colocando al paciente en posición de Lloyd-Davis. Se realizó la instalación de los trócares laparoscópicos con la técnica de 5 puertos para resección anterior baja de recto. Luego del control vascular a nivel de la raíz de los vasos mesentéricos inferiores y posterior a la disección del mesorrecto, se realizó la medición y laparotomía de $5 \mathrm{~cm}$ del tipo Pfannenstiel para insertar el cabezal de la engrapadora (Figura 1) y la extracción de la pieza operatoria. Al momento de acceder a la cavidad intraabdominal, se instaló un sistema retractor de heridas abdominales (ALEXIS® Wound Retractor, Applied Medical) y se efectuó un corte en el dedo medio de un guante de látex, a través del cual se insertó la cabeza de la engrapadora curva Contour ${ }^{\circledR}$, fijándola al dedo seccionado mediante una sutura reabsorbible para evitar la fuga de $\mathrm{CO}_{2}$ (Figura 2). La muñeca del guante es ensamblada de forma circular al sistema retractor ALEXIS ${ }^{\circledR}$, permitiendo el reini-

*Recibido el 11 de julio de 2010 y aceptado para publicación el 12 de septiembre de 2010.

Correspondencia: Dr. George Pinedo M.

Marcoleta 350, Santiago, Chile.

gpinedo@med.puc.cl 
cio del neumoperitoneo. (Figura 3). Así, la porción cefálica de la engrapadora Contour es llevada hacia la pelvis bajo visión laparoscópica, "envolviendo" al recto inferior en su totalidad (Figura 4), descendiendo el botón de seguridad para evitar el corte incompleto del recto. La movilización de la engra-

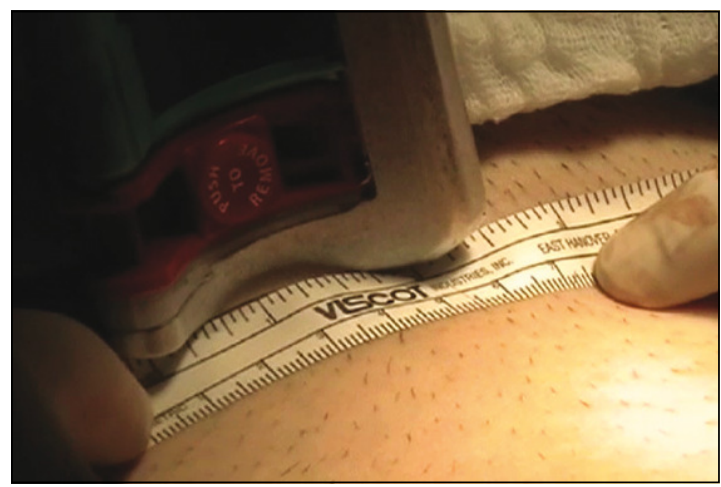

Figura 1. Medición del cabezal de Contour® para laparotomía.

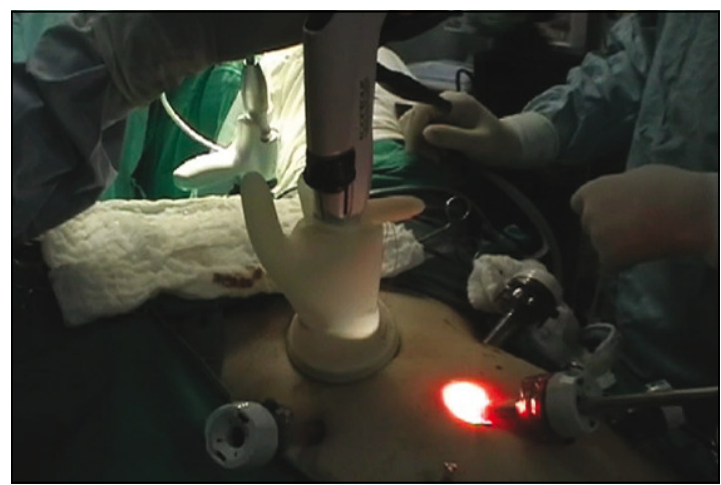

Figura 3. Visión exterior de la instalación de Contour $₫$ y sistema retractor Alexis ${ }^{\circledR}$.

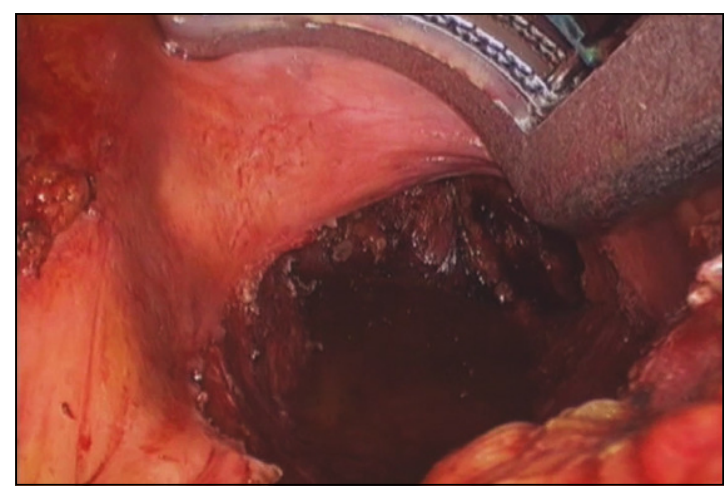

Figura 5. Sección completa del recto inferior bajo visión laparoscópica. padora se realiza de forma fluida y con facilidad por parte de operador a través del guante, el que otorga hermeticidad al neumoperitoneo. Posteriormente se lleva a cabo la sección completa del recto (Figura 5) y una anastomosis mecánica con engrapadora circular (Figura 6).

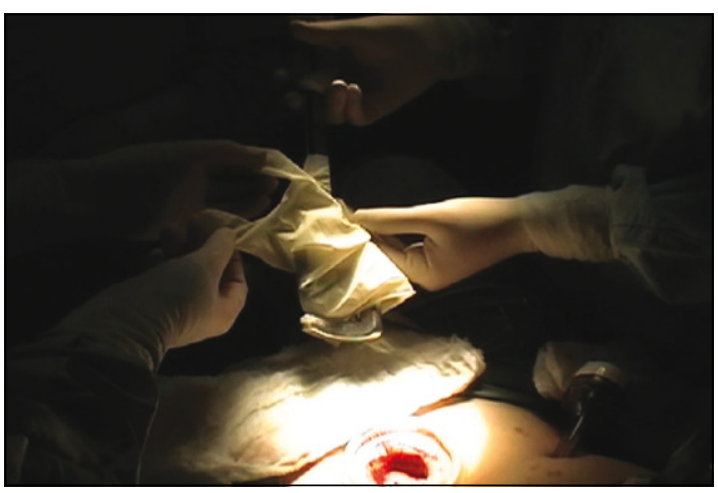

Figura 2. Sección del guante de látex y fijación hermética a Contour ${ }^{\circledR}$ con sutura reabsorbible.

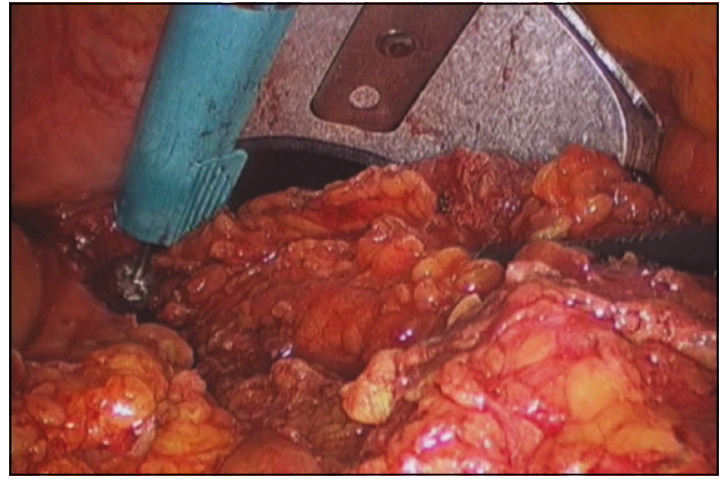

Figura 4. Visión laparoscópica de la sección del recto inferior.

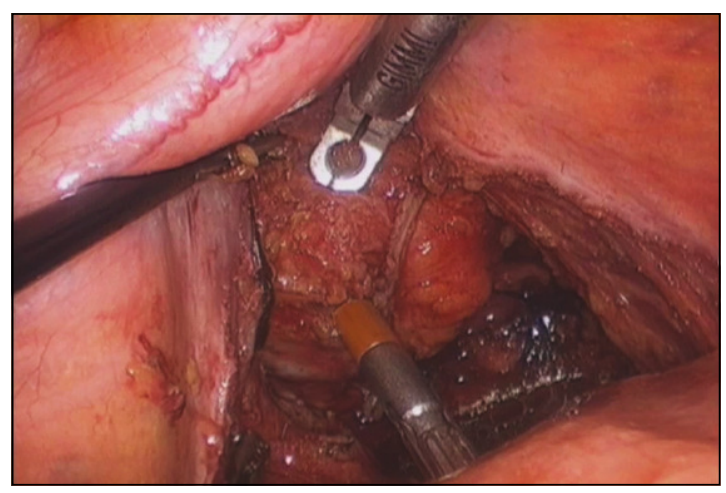

Figura 6. Ensamble de engrapadora circular. 


\section{Comentarios}

La sección del recto inferior y su posterior anastomosis es quizás la parte más difícil y desafiante de la resección anterior baja por vía laparoscópica, ya que se relaciona tanto a la tasa de filtración anastomótica como a la recidiva local ${ }^{3}$. Históricamente, la sección de recto se ha llevado a cabo mediante instrumentos utilizados en cirugía abierta y a través de una pequeña laparotomía. Sin embargo, en la mayoría de los casos no es fácil obtener una buena visualización a través de este abordaje, con tasas de conversión reportadas de $15 \%$ debido a estas dificultades técnicas ${ }^{4}$. Es por ello que el uso de la laparoscopia y la magnificación de imágenes son beneficiosas para lograr una sección del recto inferior más segura. Esto último además ha ido de la mano con la mejoría en la calidad de las suturas y de las engrapadoras mecánicas. Destacamos que los modelos curvos o Contour ${ }^{\circledR}$ permiten un corte único, a la vez que un acceso más profundo en resecciones bajas, ajustándose a la forma y anatomía de la pelvis menor. Aunque las engrapadoras lineales articuladas están disponibles en el mercado, se requiere de dos, tres y hasta cuatro cortes escalonados del instrumental laparoscópico, lo que resulta en un corte anfractuoso, asociado a un alto riesgo de recidiva local (por el acercamiento tumoral) y de filtración anastomótica. Sólo existe un estudio randomizado que compara las engrapadoras lineales versus las curvas, no observando una clara superioridad de una sobre otra, pero demuestra que estas últimas son seguras y efectivas en cuanto a asegurar un buen corte, una sección homogénea y un engrapado del recto en resecciones anteriores bajas ${ }^{2}$.

Creemos que esta técnica para la sección del recto ultrabajo por vía laparoscópica otorga mayores facilidades y garantías oncológicas que las técnicas conocidas hasta este momento.

\section{Referencias}

1. Heald R, Husband E, Ryall R. The mesorectum in rectal cancer surgery-the clue to pelvis recurrence. Br J Surg. 1982;69:613-6.

2. Lee W, Lee W, Chun H, Yun S, Cho Y, Yun H. Curved cutter stapler vs. Lineal stapler in rectal cancer surgery: a pilot prospective randomized study. Int J Colorectal Dis. 2009;24:1327-32.

3. Branagan G, Finnis D. The Wessex Colorectal Cancer Audit Working Group. Prognosis after anastomotic leakage in colorectal surgery. Dis Colon Rectum 2005;48:1021-6.

4. Targarona E, Balague C, Martínez C, Hernández M, Trias M. Laparoscopic low rectal anastomosis using a new stapler device: Early experience with the Contour stapler. Minim Invasive Ther Allied Technol. 2008;17:155-9. 